\title{
THE OCCURRENCE OF BAMBLE DISEASE (EPIDEMIC PLEURODYNIA) IN NORWAY
}

by

TH. M. VOGELSANG

IN 1962 the New York Academy of Sciences arranged a conference on Comparative Virology. During this conference Hildegard Plager ${ }^{1}$ read an interesting paper on 'The Coxsackie Viruses'. These viruses have been subdivided into two groups, $\mathbf{A}$ and B. Infections caused by B viruses include epidemic pleurodynia. She started the epidemiological part of her paper in this way: 'The first description of epidemic pleurodynia, originally known as Bornholm disease, came from Norway in 1872.'

The disease which occurred in Norway in 1872 was first described by Daae ${ }^{2}$. As the first case occurred in a little place called Bamble, the common Norwegian name for the disease is Bamble disease. The first case which was recorded on Bornholm occurred about sixty years later. Bornholm belongs to Denmark, and in 1930 a Danish doctor, Sylvest ${ }^{3}$, proposed giving the disease a Danish name, Bornholm disease.

Before Sylvest gave the disease this name, several epidemics had already been described in Norway. Unfortunately, these papers were written in Norwegian only and thus published only in Norwegian medical journals. For this reason they have remained almost unknown outside this country. In this paper I will therefore try to give a historical review of the occurrence and epidemiology of this disease in Norway.

In the middle of the last century the medical administrative district of Kragerö in Southern Norway covered a wide area of about 1,640 square kilometres with a population of about 17,000. Most of the inhabitants were scattered over the district on their farms, and there was only one small town by the coast, Kragerö itself, with barely 4,000 inhabitants. In this district Homann was the medical officer of health from 1860 to 1880 . He maintained repeatedly that more reliable observations on the causes and modes of dissemination of disease could be obtained better and with far greater certainty under the limited and transparent conditions in rural Norway than in the towns.

Homann was born in Kragerö where his father had been medical officer of health. He was therefore well known in the district. The population had unbounded faith in both father and son and was therefore able to assist them in many ways with valuable information and observations.

In 1859 there was a large dysentery epidemic in the district, and in 1864 some cases of typhoid appeared. The disease rapidly assumed epidemic proportions. Homann, together with his assistant, Hartwig, made comprehensive studies of the behaviour of these diseases in this district and gave detailed descriptions of them.,6 These two Norwegian medical practitioners must certainly be regarded as pioneers in the field of epidemiology, possessing a clear and sure conception of the aetiological importance of contagium vivum in these diseases. 


\section{The Occurrence of Bamble Disease in Norway}

In 1872 Homann was called to a farmer and observed a disease which he had never seen before. This disease had during the past weeks assumed epidemic proportions in that part of his district and was shown to be infectious. A week later Homann was informed that another practitioner in Kragerö, Daae, had observed similar cases in his practice. He therefore asked Daae to make investigations as to the infectiousness and character of the disease the next time he visited these places, and to report the results to him. This report from Daae ${ }^{2}$ to Homann was published in a Norwegian medical journal in 1872 and has the following heading: 'Epidemic in Drangedal of acute muscular rheumatism spread by infection'. It is the first published communication about this disease. It is, however, possible that Jón Finsen had observed epidemics of a similar disease in Iceland in 1856 and 1865, but these are first mentioned in 1874.

Daae started his report by mentioning that he in his practice had observed a disease which, because of its epidemic occurrence and its infectiousness, deserved attention.

The disease seemed to be an acute rheumatic infection of the muscles of the chest, the back, and partly also the abdomen. It was impossible for him to decide which special muscles were affected, but he regarded the intercostal muscles to be coaffected because of great breathing difficulties and severe pain on movement of the thorax. The disease was sometimes of sudden onset but occasionally it started after a few days' discomfort. Fever was present and the general health was much affected. The duration of the disease was from a few days up to two weeks. Relapses were common. There were no deaths. The individuals attacked were aged from one year upwards, none being older than forty years. The incubation period was very short.

After Daae had handed in his report, he continued to study the epidemiology of the disease in detail and published his results in the same medical journal two months after his first communication. ${ }^{8}$

The first case which was recorded was on a farm in a little place called Bamble. A female servant became ill on 13 May 1872 with pains in her back, chest and shoulders. She also had difficulty breathing, but no cough. She was very ill and stayed in bed for about two weeks. Three days after the onset of the disease, her mistress made a Whitsun excursion to another farm. Here she developed the same symptoms as her servant, and transferred the disease to several other guests on the farm. But it was not until there had been a wedding party in the neighbourhood that the disease reached epidemic proportions. Daae followed the cases from house to house and from place to place. He supplemented his publication with a chart of the district on which arrows marked the route of spread of infection. He recorded 290 cases in all, of which sixteen were over forty years of age. The incubation period was on an average two to three days.

In the same number of the medical journal Homann ${ }^{9}$ published a report to the Norwegian Health Department about this new disease. Like Daae he made comprehensive epidemiological investigations, and he was able to show that the epidemic had run an uninterrupted course, being transmitted by infection from patient to patient for a period of three summer months during which there were 474 victims. In the main parish of his district 346 cases were recorded in a population of 1,947. In some regions there was scarcely a house without a case. Homann was of the opinion that the large number of infections was due partly to the great infectiousness of the 


\section{Th. M. Vogelsang}

disease and partly to the low resistance to the infection in the population. In addition, although the people some time after the wedding became aware of this infectiousness, they did not try to isolate the patients, but kept up contact, as usual, with infected households.

Two years later Daae ${ }^{10}$ published a new communication about the disease. In 1873 he had observed thirty-six new cases, but only two of them occurred in places where the large epidemic had raged in 1872.

Meanwhile, Daae's and Homann's communications called the doctors' attention to the disease. It seems from the official medical reports that the disease occurred in different parts of Southern Norway in the following years up to 1878 . Thereafter there were no reports of the occurrence of the disease until 1896, when Backer ${ }^{11}$ described an epidemic which occurred in Southern Norway in June and July. In his own district 470 cases were notified. He was, however, of the opinion that the total number was much higher, as many of the patients did not call the doctor. He also knew from his own experience that on many farms the whole family had been attacked by the disease. The symptoms were the same as in the above-mentioned epidemics, but in addition there were some transient complications such as pleurisy, pericarditis and two cases of orchitis. There were no deaths.

In the official medical reports from the same year, the disease is again mentioned from the administrative district where Backer had his practice. In this year 997 cases of influenza, of which the majority occurred during the summer months, were also notified in this district. Among these were numerous cases which are described as epidemic or febrile rheumatism. During the months from June to October this peculiar disease was of epidemic occurrence in several places within the two districts, especially in the town Skien and in Bamble, where the first case had occurred in 1872.

In the following years all the cases which occurred in Norway were notified in the obligatory annual reports to the Health Department under the heading 'Bamble disease'. In 18974,158 cases were notified. They all occurred in Southern Norway and 3,758 of the cases occurred during the summer months of June to September. In the towns 2,241 cases were notified and 1,917 cases in rural districts. There were no deaths. In 1898 only thirty-seven cases were notified and in 1899 nineteen cases. Later Bamble disease was not put on the tables of epidemic diseases in the annual reports from the Norwegian Health Department, but some of the medical officers of health in Southern Norway mentioned in their annual reports to the Health Department that the disease had occurred in their districts.

In the summer 1922 an epidemic of Bamble disease occurred among cadets and medical students in a training camp in Southern Norway. ${ }^{12}$ The clinical picture was similar to the earlier epidemics with an acute fever, setting in very suddenly, but lasting only two to three days. Often relapses were seen up to four days after the first attack. The patients complained mainly of headache, pains in the muscles of the chest and the back, and difficulty with breathing. In three cases a dry pleurisy was noted and in one case orchitis. The disease lasted from four to ten days, and its course was rather mild. Of 278 soldiers in the camp, forty-four or fifteen per cent, were attacked but no deaths occurred.

After discussing the aetiology of the disease, Thjötta and Salvesen ${ }^{12}$ found that 


\section{The Occurrence of Bamble Disease in Norway}

none of the common diseases in Norway could be said to be identical with the disease studied. They further stated that Phlebotomus fever (sandfly fever, pappataci fever or three-day fever) seen in warm countries gives a picture clinically and epidemiologically so similar to Bamble disease that if the latter had occurred in a warm country, it would without doubt have been diagnosed as Phlebotomus fever. The cause of the above disease is a filtrable agent present in the blood of patients on the first day of the fever and the vector is Phlebotomus papatasi. The disease can therefore not be transmitted from person to person, but must have an intermediary host just like malaria and yellow fever. In 1922 Bamble disease occurred only in the camp and did not infect the surrounding population, or the officers who lived in another part of the camp. These circumstances speak against air-borne infection. Thjötta and Salvesen therefore put the question as to whether there might be an insect-borne disease in Norway resembling pappataci fever in warm countries.

In 1922 Löken $^{13}$ gave a review of the occurrence of Bamble disease in Norway and a detailed description of the clinical picture. He pointed out that relapses, once or in some cases several times, are the distinctive feature of the disease.

Sylvest's first description of the disease is contained in a short publication in 1930: 'A Bornholm epidemic-myositis epidemica.'13 During his summer holidays on Bornholm he observed an epidemic disease which he had neither seen nor read about earlier and he described the historia morbi of twenty-three cases. This description he showed to a Professor of Internal Medicine from Copenhagen, Carl Sonne, who also spent his vacation on Bornholm that summer. He was then informed that a similar disease had occurred earlier in Norway.

In his communication he reported Daae's publication from 1872 and mentioned that the disease had been called 'Bamble disease' in Norway. As far as he knew, the disease had no Danish name, and he therefore proposed, after the analogy of the Norwegian denomination, to call it 'The Bornholm disease'.

Two weeks later Voss ${ }^{14}$ published a short note in the same journal under the heading: 'Myositis epidemica, Bornholm disease, called Taarbæk disease 33 years ago'. He describes a similar disease which occurred in Taarbæk on Zealand, Denmark, in 1897. The number of cases was about one hundred. In his professional register for that year he had called the disease 'Rheumatismus muscularis intercostalis febrilis epidemicus', but the common name among the population was 'Taarbæk disease'. Bornholm disease is therefore not the original Danish name for the disease, but it has become used because Sylvest in 1933 gave his doctoral thesis the title: 'Bornholm disease-myalgia epidemica'.15

The viral aetiology of the disease was first established in 1949. The agent then isolated was found to be Coxsackie $B$ 1. Later similar outbreaks have been caused by other viruses within group $B$. The scientific name of the disease is now commonly Pleurodynia epidemica, but should it in addition have a more popular name, it is not logical to call it 'Bornholm disease', but the original common Norwegian name 'Bamble disease', after the place where the first case was observed in 1872.

\section{REFERENCES}

1. Plager, H., 'The Coxsackie Viruses'. Ann. N. Y. Acad. Sci., 1962, 101, 390-97. 


\section{Th. M. Vogelsang}

2. DAAE, A., 'Epidemi i Drangedal af akut Muskelreumatisme, udbredt ved Smitte' [Epidemic in Drangedal of acute muscular rheumatism spread by infection], Norsk Mag. Lagevidensk, Series 3, 1872, 2, 409-13.

3. Sylvest, E., 'En Bornholmsk Epidemi. Myositis epidemica' [A Bornholm epidemicmyositis epidemica], Ugeskr. Lag., 1930, 92, 798-801.

4. Homann, C. and HaRtwig, C., 'Om Dysenterie-Epidemien i Kragerös Lægedistrict i 1859' [The dysentery epidemic in the medical district of Kragerö in 1859], Norsk Mag. Lagevidensk, Series 2, 1860, 14, 217-70, 297-359.

5. Homann, C. AND HaRTwig, C., 'Meddelelse om Nervefeberen i Kragerö Lægedistrikt Aar 1864' [Contribution to the occurrence of typhoid fever in the medical district of Kragerö in the year 1864], Norsk Mag. Lagevidensk, Series 2, 1865, 19, 433-501.

6. HomanN, C. AND Hartwig, C., 'Meddelelse om Nervefeberen i Kragerö Lægedistrikt. Aarene 1865 og 1866' [Contribution to the occurrence of typhoid fever in the medical district of Kragerö in the years 1865 and 1866], Norsk Mag. Lagevidensk, Series 2, 1867, 21, 273-316.

7. Vogelsang, Th. M., Typhoid and Paratyphoid B Carriers and their Treatment, Universitas Bergensis. Series medica No. 1, 1950, 1-368.

8. DAAE, A., 'Om den smitsomme Muskelreumatisme og deres udbredning hovedsagelig i Drangedal' [The infectious muscular rheumatism and its spread chiefly in Drangedal], Norsk Mag. Lagevidensk, Series 3, 1872, 2, 529-42.

9. HomanN, C., 'Om en i Kragerö Læagedistrikt herskende smitsom Febersygdom' [On an infectious febrile disease occurring in the medical district of Kragerö], Norsk Mag. Lagevidensk, Series 3, 1872, 2, 542-55.

10. DAAE, A., 'Epidemi af akut Muskelreumatisme i Kragerö Lægedistrikt' [Epidemic of acute muscular rheumatism in the medical district of Kragerö], Norsk Mag. Laegevidensk, Series 3, 1874, 4, 551-59.

11. BACKER, A., 'Epidemi af akut Muskelrheumatisme' [Epidemic of acute muscular rheumatism], Norsk Mag. Lagevidensk, Series 4, 1896, 11, 1234-38.

12. Thuötta, Th. and Salvesen, H. A., 'En epidemi av Bamblesyke blandt kadetter og medicinere i Fredriksværn, sommeren 1922' [An epidemic of 'Bamble disease' among cadets and medical students in a training camp in Norway], Nord. hyg. T., 1923, 4, 243-62.

13. LöKEN, K., 'Litt om Bamblesyken' [Some words on 'Bamble disease'], T. norske Lageforen, 1928, 48, 833-40.

14. Voss, A., 'Myositis epidemica. Den bornholmske syge hed for 33 aar siden den taarbakske syge' [Myositis epidemica. Bornholm disease, called Taarbæk disease 33 years ago], Ugeskr. Lag,. 1930, 92, 843-44.

15. Sylvest, E., Den Bornholmske Syge-Myalgia epidemica. [Bornholm disease-Myalgia epidemica], Doctoral thesis, Copenhagen, 1933. 